\title{
UJI EFEK PEMBERIAN EKSTRAK BIJI PETAI CINA (Leucaena leucochepala L) TERHADAP KADAR GULA DARAH TIKUS WISTAR (Rattus norvegicus) YANG DIINDUKSI DENGAN ALOKSAN
}

\author{
Mahesti Utami \\ Mona P. Wowor \\ Christi Mambo \\ ${ }^{1}$ Kandidat Skripsi Fakultas Kedokteran Universitas Sam Ratulangi Manado \\ ${ }^{2}$ Bagian Farmakologi dan Terapi Fakultas Kedokteran Universitas Sam Ratulangi \\ Email: mahestiutami@gmail.com
}

\begin{abstract}
Public believes that Lead Tree seeds (Leucaena leucochepala L) as a kind of medicinal plant that have capability of treating a lot of diseases, among them is diabetes. This study aimed to test whether the Lead tree seeds extract can reduce blood glucose levels of Wistar rats (R. norvegicus) which has induced alloxan. The subjects in these research were male wistar rat with total of 18 samples divided into six groups consisting of a negative control group and five groups induced by alloxan with dose $130 \mathrm{mg} / \mathrm{kgBW}$ of rat, which can cause wistar rats in hyperglycemic state. Hyperglycemic rats were given lead tree seed extract at a dose of $0,14 \mathrm{mg} / 200 \mathrm{gBW}, 0,3 \mathrm{mg} / 200 \mathrm{gBW}$, and 0,6 mg/200 gBW, positive control group was given insulin analogue, and one group was given alloxan. Data obtained from the examination of blood glucose levels in all groups of Wistar rats on day zero, day one and day two every six hours on $0,6,12,18$, and 24 . The results showed that giving lead tree seed extract does not have the effect to reduce blood glucose levels Wistar rats.
\end{abstract}

Keywords: leucaena leucochepala L., lead tree seed, bood glucose level, alloxan

\begin{abstract}
Abstrak: Biji petai cina (Leucaena leucochepala L)diyakini masyarakat sebagai salah satu tanaman obat yang mampu mengobati berbagai penyakit, salah satunya diabetes. Penelitian ini bertujuan untuk menguji apakah pemberian ekstrak biji petai cina dapat menurunkan kadar glukosa darah tikus Wistar ( $R$. norvegicus) yang diinduksi aloksan. Subjek penelitian berupa tikus Wistar jantan berjumlah 18 ekor yang dibagi dalam 6 kelompok, terdiri atas satu kelompok kontrol negatif dan lima kelompok tikus Wistar yang diberi aloksan dengan dosis $130 \mathrm{mg} / \mathrm{kgBB}$ yang menyebabkan tikus Wistar dalam keadaan hiperglikemik. Tikus hiperglikemik diberi ekstrak biji petai cina dengan dosis 0,14 mg/200 gBB tikus, 0,3 mg/200 gBB tikus, dan 0,6 mg/200 gBB tikus, kelompok kontrol positif diberi analog insulin, dan satu kelompok hanya diberi aloksan. Data diperoleh dari pemeriksaan kadar glukosa darah pada semua kelompok tikus Wistar pada hari ke nol, pertama, dan kedua pada jam ke-0, 6, 12, 18, dan 24. Hasil penelitian menunjukkan bahwa pemberian ekstrak biji petai tidak mempunyai efek menurunkan kadar glukosa darah tikus Wistar.
\end{abstract}

Kata kunci: leucaena leucochepala L., biji petai cina, kadar gula darah, aloksan

Diabetes melitus (DM) merupakan suatu kelompok penyakit metabolik dengan karakteristik hiperglikemia yang terjadi karena kelainan sekresi insulin, kerja insulin atau kedua-duanya. DM adalah gangguan metabolisme yang secara genetis dan klinis termasuk heterogen dengan manifestasi berupa hilangnya toleransi karhohidrat. ${ }^{1,2}$

Berdasarkan penelitian epidemiologi menurut World Health Organization (WHO) memprediksi kenaikan jumlah 
penderita DM di Indonesia dari 8,4 juta pada tahun 2000 menjadi sekitar 21,3 juta pada tahun 2030. Berdasarkan laporan Riset Kesehatan Dasar (RISKESDAS) tahun 2013 prevalensi diabetes melitus tertinggi terdapat di Yogyakarta (2,6\%), DKI Jakarta (2,5\%), Sulawesi Utara (2,4\%), dan Kalimantan Timur (2,3\%). ${ }^{3,4}$

Pengobatan DM dapat dilakukan secara medis dengan obat-obatan modern atau suntikan tetapi karena tingginya biaya pengobatan medis ini terkadang sulit dilakukan. DM juga dapat di atasi dengan pengobatan tradisional dengan memanfaatkan tanaman obat berkhasiat. ${ }^{5}$

Salah satu tanaman yang digunakan secara empirik untuk mengatasi penyakit diabetes mellitus adalah biji petai Cina (Leucaena leucocephala L). ${ }^{6}$

\section{METODE PENELITIAN}

Penelitian ini menggunakan metode eksperimental. Penelitian ini dilakukan sejak bulan September 2014 - Januari 2015 di Laboratorium Farmakologi dan Terapi Fakultas Kedokteran Universitas Sam Ratulangi. Subjek penelitian terdiri dari 18 ekor tikus Wistar jantan.

\section{Alat dan Bahan Penelitian}

Alat yang digunakan dalam penelitian ini terdiri dari wadah plastik, kawat kasa, botol minuman, wadah makanan, oven, blender, corong pemisah, kertas saring, cawan petri, labu erlenmeyer, timbangan analitik, batang pengaduk, gelas ukur, glukometer, gunting, kapas, stopwatch, sonde lambung, dan semprit $1 \mathrm{ml}$. Bahan yang digunakan terdiri dari bawang putih, etanol 70\%, aloksan, analog insulin, aquades, dan pakan AD2.

\section{Hewan Uji}

Hewan uji dibagi dalam enam kelompok.Sebelum pengukuran pada hari ke nol (H0), semua tikus dipuasakan selama 12 jam. Setelah 12 jam kadar glukosa darah puasa semua tikus diperiksa, setelah itu satu kelompok tikus hanya diberikan aquades sedangkan lima kelompok tikus diberikan aloksan dengan dosis $130 \mathrm{mg} / \mathrm{kgBB}$ tikus untuk menginduksi kerusakan sel B pankreas sehingga glukosa darah tikus meningkat. Kadar glukosa darah semua tikus diperiksa kembali pada hari pertama (H1) setelah 24 jam pemberian aloksan dan pada awal hari kedua (H2) jam ke-0. Setelah kadar glukosa darah diukur, semua kelompok tikus diberikan perlakuan. Kelompok kontrol positif diberikan analog insulin dengan dosis 0,7 U/kgBB tikus, dan tiga kelompok diberikan ekstrak biji peti cinadenga $n$ dosis $0,14 \mathrm{mg} / 200 \mathrm{gBB}$ tikus, $0,3 \mathrm{mg} / 200$ gBB tikus, dan 0,6 mg/200 gBB tikus. Kadar glukosa darah pada semua tikus kemudian diperiksa pada jam ke-6, 12, 18, dan 24. Semua sampel darah diambil dari pemotongan ujung ekor tikus dan kadar glukosa darah diukur dengan glukometer.

\section{Penentuan Dosis dan Pemberian Aloksan}

Penelitian ini menggunakan aloksan dengan dosis $130 \mathrm{mg} / \mathrm{kgBB}$. Aloksan diberikan secara intraperitoneal pada perut tikus bagian bawah.

\section{Penentuan Dosis dan Pemberian Analog Insulin}

Berat badan rata-rata manusia dewasa di Indonesia adalah $50 \mathrm{~kg}$. Dosis yang digunakan untuk manusia dewasa yang memiliki kadar glukosa darah $>180 \mathrm{mg} / \mathrm{dL}$ adalah $6 \mathrm{U}$ novomix. Maka dosis yang digunakan pada manusia adalah: $6 \mathrm{U} / 50 \mathrm{~kg}$ $=0,12 \mathrm{U} / \mathrm{kgBB}$. Digunakan rumus Human Equivalent Dose (HED) based on Body Surface Area (BSA), ${ }^{7}$ maka didapatkan hasil: Dosis manusia $\times \mathrm{Km}$ faktor manusia/ Km faktor tikus. $0,12 \times 37 / 6=0,74 \mathrm{U}$ dibulatkan 0,7 U/kgBB tikus. Analog insulin diberikan secara subkutan.

\section{Ekstrak Biji Petai Cina}

Biji petai cina yang sudah dikeringkan dalam oven dengan suhu $40^{\circ} \mathrm{C}$ selama \pm 2 hari dihaluskan dengan menggunakan blender. Tepung biji petai cina diekstraksi dengan cara maserasi menggunakan 1600 ml etanol 70\%. 
Setelah dimaserasi selama 10 hari (diaduk \pm 15 menit/hari),larutan disaring menggunakan kertas saring. Filtrat kemudian ditempatkan dalam cawan petri dan diuapkan sampai didapatkan ekstrak pekat sebanyak 29,67 gram. Ekstrak inilah yang digunakan dalam penelitian.

\section{Penentuan Dosis dan Cara Pemberian Ekstrak}

Dosis empiris yang biasa digunakan pada orang Indonesia adalah 1 sendok (15 g) dan di seduh dengan air panas. ${ }^{5}$ Nilai konversi perhitungan dosis pada manusia dengan berat badan $70 \mathrm{~kg}$ dan tikus $200 \mathrm{~g}$ ialah $0,018 .^{8}$

Dosis pada manusia $=\frac{\text { berat ekstrak pekat biji petai cina }}{\text { berat biji petai } \text { cina }} \times$ dosis manusia.

Dosis pada manusia $=\frac{29,67 \mathrm{gram}}{2000 \mathrm{gram}} \times 15 \mathrm{gram} / \mathrm{hari}=0,22 \mathrm{gram} / \mathrm{hari}=220 \mathrm{mg} / \mathrm{hari}$.

Dosis pada tikus $=\frac{50}{70} \times 0,018 \times 220=2,82 \mathrm{mg} / 200$ gram tikus $/$ hari.

Di buat sediaan $1000 \mathrm{mg}$ ekstrak pekat dan di larutkan dengan $100 \mathrm{ml}$ aquades.

Dosis $\mathrm{I}=\frac{1,4}{1000} \times 100 \mathrm{ml}=0,14 \mathrm{ml}$

Dosis II $=\frac{2,82}{1000} \times 100 \mathrm{ml}=0,3 \mathrm{ml}$

Dosis III $=\frac{5,60}{1000} \times 100 \mathrm{ml}=0,6 \mathrm{ml}$

Ekstrak biji Petai Cina diberikan secara oral dengan menggunakan NGT dan semprit. NGT dimasukkan melalui mulut sampai ke lambung.

\section{HASIL PENELITIAN}

Pengukuran kadar glukosa darah dilakukan sebanyak 7 kali yaitu hari ke nol (H0), hari pertama (H1), hari kedua (H2) jam ke-0 sebelum perlakuan dan jam ke-6, 12, 18, dan 24 setelah perlakuan. Kelompok satu (K1) merupakan kelompok kontrol negatif yaitu kelompok yang hanya diberikan aquades, kelompok dua (K2) merupakan kelompok kontrol positif yaitu kelompok yang diberikan aloksan dan analog insulin, kelompok tiga (K3) merupakan kelompok yang hanya diberikan aloksan, kelompok empat (K4), lima (K5), dan enam (K6) merupakan kelompok perlakuan yang diberikan dosis ekstrak biji petai cina yang berbeda yaitu $0,14 \mathrm{mg} / 200$ $\mathrm{gBB}, 0,3 \mathrm{mg} / 200 \mathrm{gBB}$, dan $0,6 \mathrm{mg} / 200$ gBB. Hasil pengukuran seluruh kelompok dapat dilihat pada Tabel 1.

\section{BAHASAN}

Hasil pengukuran kadar glukosa darah pada kelompok satu yaitu kelompok kontrol negatif yang hanya diberikan aquades, dari hari ke nol hingga hari kedua jam ke-24 tidak menunjukkan adanya kenaikan atau penurunan kadar gula darah yang bermakna. Kadar gula darah tikus tidak menunjukkan kenaikan yang signifikan karena tidak diberikan makanan sehingga tidak ada masukan glukosa ataupun agen diabetogenik yang dapat mempengaruhi kadar gula darah tikus

Kadar glukosa darah hewan uji pada kelompok dua yaitu kelompok kontrol positif mengalami penurunan pada hari kedua jam ke-6, 12, dan 18 setelah pemberian analog insulin. Hal ini dikarenakan novomix adalah insulin analog yang dapat menurunkan kadar gula darah pada hewan uji. Novomix adalah insulin campuran (mixed atau premixed insulin) yaitu campuran dua macam insulin yang short-acting dan intermediate-acting. Efek puncak tercapai dalam dua fase, yaitu 3 jam dan 8-12 jam setelah suntik dan berakhir setelah 24 jam sehingga kadar gula darah ketiga tikus kelompok kontrol positif terjadi kenaikan pada jam ke 24.Insulin reaksi pendek memiliki sifat transparan dan mulai bekerja dalam tubuh dalam waktu 30 menit sejak disuntikkan ke dalam tubuh. 
Insulin ini bekerja secara maksimal selama 1 sampai 3 jam dalam aliran darah dan segera menghilang setalah 6 sampai 8 jam kemudian. Sedangkan insulin reaksi menengah adalah insulin yang mulai efektif bekerja menurunkan gula darah sejak 1 sampai 2 jam setelah disuntikkan ke dalam tubuh. Obat ini bereaksi secara maksimal selama 6 sampai 10 jam, dan berakhir setelah 10 sampai 16 jam setelahnya. Berdasarkan waktu yang diperlukan dalam bekerja, insulin terbagi dalam 4 jenis insulin yaitu reaksi pendek, reaksi panjang, reaksi menengah dan reaksi cepat. ${ }^{9}$

Pengukuran kadar gula darah pada tikus kelompok ketiga yang hanya diberikan aloksan menunjukkan kenaikan kadar gula darah yang signifikan. Kenaikan kadar gula darah ini dipengaruhi oleh pemberian aloksan yang bereaksi dengan merusak substansi esensial di dalam sel beta pankreas sehingga menyebabkan berkurangnya granula-granula pembawa insulin di dalam sel beta pankreas. ${ }^{10}$

Pada kelompok perlakuan yang diberikan ekstrak biji petai cina dengan dosis $0,14 \mathrm{mg} / 200 \mathrm{gr}$ tikus, 0,3 mg/ $200 \mathrm{gr}$ tikus dan dosis $0,6 \mathrm{mg} / 200$ gr tikus tidak menunjukkan efek penurunan kadar gula darah tikus yang di induksi aloksan. Hal tersebut kemungkinan dipengaruhi oleh jumlah dosis setiap kelompok perlakuan yang terlalu sedikit dan teknik penyuntikkan yang kurang baik sehingga aloksan yang disuntikkan tidak dapat mempengaruhi kadar gula darah tikus.

Tabel 1. Hasil Pengukuran Kadar Gula Darah Semua Kelompok Perlakuan

\begin{tabular}{|c|c|c|c|c|c|c|c|c|}
\hline \multirow[b]{2}{*}{ Kelompok } & \multirow[b]{2}{*}{ Tikus } & \multirow[b]{2}{*}{$\mathrm{HO}$} & \multirow[b]{2}{*}{ H1 } & \multicolumn{5}{|c|}{$\mathrm{H} 2$} \\
\hline & & & & $\begin{array}{c}0 \\
\text { (mg/dl) }\end{array}$ & $\begin{array}{c}6 \\
\text { (mg/dl) }\end{array}$ & $\begin{array}{c}12 \\
\text { (mg/dl) }\end{array}$ & $\begin{array}{c}18 \\
(\mathrm{mg} / \mathrm{dl})\end{array}$ & $\begin{array}{c}24 \\
(\mathrm{mg} / \mathrm{dl})\end{array}$ \\
\hline \multirow{4}{*}{$\begin{array}{c}\text { Kelompok } \\
\text { Aquades }\end{array}$} & N1 & 119 & 121 & 69 & 59 & 103 & 78 & 86 \\
\hline & N2 & 102 & 89 & 124 & 106 & 125 & 120 & 90 \\
\hline & N3 & 80 & 116 & 107 & 67 & 94 & 90 & 90 \\
\hline & Rata-rata & 100,33 & 108,66 & 100 & 77,33 & 107,33 & 96 & 88,66 \\
\hline \multirow{4}{*}{ Kontrol Positif } & $\mathrm{P} 1$ & 81 & 190 & 476 & 450 & 371 & 87 & 600 \\
\hline & P2 & 74 & 186 & 600 & 600 & 361 & 56 & 436 \\
\hline & P3 & 116 & 146 & 499 & 369 & 212 & 84 & 509 \\
\hline & Rata-rata & 90,33 & 174 & 525 & 473 & 314,66 & 75,66 & 515 \\
\hline \multirow{4}{*}{ Kontrol Negatif } & KA1 & 106 & 181 & 230 & 287 & 321 & 600 & 600 \\
\hline & KA2 & 75 & 544 & 550 & 554 & 581 & 600 & 600 \\
\hline & KA3 & 77 & 167 & 283 & 300 & 428 & 591 & 600 \\
\hline & Rata-rata & 86 & 297,33 & 354,33 & 380,33 & 443,33 & 597 & 600 \\
\hline \multirow{4}{*}{$\begin{array}{c}\text { Kelompok } \\
\text { Perlakuan I (0,14 } \\
\text { mg/200 g tikus) }\end{array}$} & A1 & 76 & 421 & 567 & 600 & 600 & 225 & 378 \\
\hline & $\mathrm{A} 2$ & 71 & 389 & 538 & 600 & 600 & 600 & 444 \\
\hline & A3 & 78 & 538 & 600 & 600 & 600 & 600 & 483 \\
\hline & Rata-rata & 75 & 449,33 & 568,33 & 600 & 600 & 475 & 433,66 \\
\hline \multirow{4}{*}{$\begin{array}{c}\text { Kelompok } \\
\text { Perlakuan II (0,3 } \\
\text { mg/200 g tikus) }\end{array}$} & B1 & 73 & 321 & 599 & 600 & 600 & 600 & 600 \\
\hline & B2 & 75 & 90 & 71 & 104 & 129 & 83 & 64 \\
\hline & B3 & 78 & 98 & 262 & 600 & 600 & 560 & 322 \\
\hline & Rata-rata & 75,33 & 169,66 & 310,66 & 434,66 & 443 & 414,33 & 328,66 \\
\hline \multirow{4}{*}{$\begin{array}{c}\text { Kelompok } \\
\text { Perlakuan III (0,6 } \\
\text { mg/200 g tikus) }\end{array}$} & C1 & 59 & 511 & 525 & 472 & 513 & 535 & 391 \\
\hline & $\mathrm{C} 2$ & 72 & 80 & 90 & 113 & 112 & 92 & 74 \\
\hline & C3 & 92 & 101 & 125 & 91 & 78 & 133 & 128 \\
\hline & Rata-rata & 74,33 & 230,66 & 246,66 & 225,33 & 234,33 & 253,33 & 197,66 \\
\hline
\end{tabular}




\section{SIMPULAN DAN SARAN}

Berdasarkan hasil penelitian maka dapat disimpulkan bahwa ekstrak biji petai cina tidak mempunyai efek menurunkan kadar gula darah tikus Wistar yang diinduksi aloksan. Perlu dilakukan penelitian lebih lanjut dengan dosis yang lebih besar. Perlu dilakukan penelitian lebih lanjut dengan teknik penyuntikkan yang lebih baik.

\section{DAFTAR PUSTAKA}

1. Purnamasari D. Diagnosis dan Klasifikasi Diabetes Mellitus. Dalam: Buku Ajar Ilmu Penyakit Dalam Edisi V Jilid III. Jakarta: Pusat Penerbitan Department Ilmu Penyakit Dalam FKUI; 2009. p. 1880.

2. Schteingart DE. Pankreas: Metabolisme Glukosa dan Diabetes Melitus. Dalam: Price SA dan Wilson LM. Patofisiologi: Konsep Klinis ProsesProses Penyakit. Jakarta: EGC; 2005. p. 1260.

3. Revisi Final Konsensus DM Tipe 2 Indonesia 2011. Didapat dari:http://www.academia.edu/40537 87/Revisi_final_KONSENSUS_DM_
Tipe_2_Indonesia_2011 [Di unduh: 19 September 2014,18:00]

4. Riset Kesehatan Dasar 2013. Badan Penelitian Dan Pengembangan Kesehatan Kementrian Kesehatan RI. Jakarta. 2013

5. Wijayakusuma H. Bebas Diabetes Mellitus Ala Hembing. Jakarta: Puspa Swara; 2004.

6. Thomas ANS. Tanaman Obat Tradisional. Volume 2. Jakarta: Kanisius; 1992.p. 91-92

7. Shannon RS, Minakshi N, Nihal A. Dose Translation from Animal to Human Studies Revisited. FASEB Journal Life Science Forum:2007;22:659-61.

8. Harmita, Radji M. Buku Ajar Analisis Hayati. Jakarta: EGC; Edisi-3.2008. p. 66

9. Tandra H. Segala Sesuatu Yang Harus Anda Ketahui Tentang Diabetes Panduan Lengkap Mengenal dan Mengatasi Diabetes Dengan Cepat dan Mudah. Jakarta: Gramedia Pustaka Utama; 2007. p. 221.

10.Yuriska A. Efek Aloksan Terhadap Glukosa Darah Tikus. Skripsi. Universitas Diponegoro Semarang; 2009. 